\title{
LA NATURALEZA DE LA VOCACIÓN EN LA ANTROPOLOGÍA DE ORTEGA Y GASSET
}

\author{
MORA PERPERE VIÑUALES \\ Pontificia Universidad Católica Argentina
}

\begin{abstract}
RESUMEN: Cuando Ortega hace referencia al concepto de vocación, expone, sobre todo, características de la misma. En ese sentido, uno puede encontrar en su obra explicaciones acerca de cómo opera la vocación, en qué medida guía al hombre en el camino hacia su propia realización, cuál es la relación de la misma con la sociedad en la cual el individuo desarrolla su vida, entre otros. Lo que no explica en ningún momento, sin embargo, es qué es la vocación, esto es, cuál es su naturaleza metafísica. Este trabajo pretende abordar esta cuestión y explicar de qué manera resulta más apropiado entenderla.
\end{abstract}

PALABRAS CLAVE: Ortega y Gasset; vocación; naturaleza metafísica; autenticidad; proyecto vital.

\section{The nature of vocation in Ortega y Gasset's anthropology}

ABSTRACT: When Ortega makes reference to the concept of vocation, he exposes, above all, characteristics of it. In that sense, we can find in his work explanations about how the vocation operates, in what sense does it guide men on the road to their own fulfillment, what is the relationship of it with the society in which the individual develops his life, among others. What he does not explain, however, is what vocation is, that is, what is its metaphysical nature. This paper aims to address this issue and explain why the nature of the vocation in Ortega's philosophy can be understood metaphysically from its instantial nature.

KEY WORDS: Ortega y Gasset; vocation; metaphysical nature; authenticity; vital project.

\section{INTRODUCCIÓN}

Entre los años 1930 y 1931, Ortega y Gasset brindaba en Madrid su conocido curso acerca de Qué es la vida ${ }^{1}$. Allí, en la séptima lección, el filósofo explicaba a sus alumnos que lo propio de la vida humana consiste, no sólo en que el hombre se encuentra inmerso en una circunstancia, sino también en el hecho de que aquella circunstancia actúa sobre él. En esta continua interacción, agregaba entonces, el hombre va descubriendo el proyecto que es por íntima necesidad y que debe realizar si desea alcanzar la autenticidad de su vida ${ }^{2}$. En ese sentido, añadía en la lección siguiente, cada uno se ve obligado a decidir constantemente lo que va a hacer y, por lo mismo, lo que va a ser. El individuo no puede simplemente «resbalar de cosa en cosa, de ocupación en ocupación, según lo que buenamente traiga el azar de cada jornada ${ }^{3}$, explicaba Ortega,

1 Se han realizado diversas ediciones de las obras completas de Ortega y Gasset. En el presente trabajo, se seguirá la edición en diez volúmenes de Taurus / Fundación José Ortega y Gasset (2004-2010). Si no se indica otra cosa, se citará siempre por esta edición señalando únicamente a pie de página título de la obra y fecha de la misma, e indicando el número de tomo en romanos y de página en arábigos.

2 «[¿QQué es la vida? Lecciones del curso 1930-1931]»(1931), o. c., VIII, 435.

3 Idem, 446. 
sino que, por el contrario, cada uno «debe acertar en su vida y en cada momento de ella» ${ }^{4}$. Ésta era la única manera de poder alcanzar una vida plena y admirable. El hecho de que estas palabras fuesen pronunciadas por Ortega en 1930 no resulta casual. Para ese momento, el filósofo había ya presentado su concepción de la vida humana como realidad radical, y había introducido un concepto que sería clave para poder comprender su concepción de la misma: el concepto de vocación individual. Por medio de este concepto, Ortega señalará una y otra vez la importancia de acertar en cada instante de la vida, tal como explicaba en aquella ocasión a sus alumnos, como único modo de que la vida individual llegue, en cada caso, a su propia plenitud.

Si bien el concepto de vocación aparece formulado como tal por un Ortega ya maduro, el mismo se enmarca en la constante llamada a la autenticidad que realiza el filósofo a lo largo de toda su obra. Sin embargo, para poder introducir este concepto y ubicarlo de manera central en su filosofía, Ortega necesitaba primero presentar la vida humana como concepto metafísico en el marco de su raciovitalismo. Esto será posible hacia finales de los años 20, momento en que él mismo afirmará: «Hay una vieja noción que es preciso rehabilitar, dándole un lugar más importante que nunca ha tenido: es la idea de vocación. No hay vida sin vocación, sin llamada íntima. La vocación procede del resorte vital, y de ella nace, a su vez, aquel proyecto de sí misma, que en todo instante es nuestra vida ${ }^{5}$.

Parece claro, entonces, que hacer referencia a la idea de vocación dentro de la filosofía de Ortega implica aproximarse a un concepto clave de todo su entramado moral. Sin embargo, en ningún momento de su obra puede encontrarse un desarrollo sistemático de este concepto, algo que, según el mismo Ortega, hubiese requerido "toda una filosofía» ${ }^{6}$. Esto ha conducido a que muchas de las preguntas que éste suscita hayan quedado abiertas. La génesis del concepto dentro de su pensamiento, el papel de la educación en la conformación de la misma, la relación entre la vocación y las creencias, son un claro ejemplo de ello. Estas cuestiones, entre otras, constituyen hasta nuestros días un objeto de discusión entre los estudiosos de la filosofía orteguiana. Sin embargo, hay uno de estos interrogantes que parece ser clave para poder comprender este concepto en toda su amplitud y cuya importancia, sin embargo, ha sido poco señalada aún: la pregunta acerca de la naturaleza metafísica de la vocación.

Este trabajo busca abordar este interrogante y, a partir de investigar las diversas respuestas que se han dado al mismo, determinar cuál es el modo más apropiado de responderlo. Para ello, en primer lugar, se realizará una primera aproximación al concepto orteguiano de vocación y se señalará la importancia del mismo en el marco de la antropología de Ortega. En segundo lugar, se presentarán las diversas respuestas que se han dado acerca de la naturaleza metafísica de la vocación. Esto permitirá, por último, explicar por

4 Idem, 445-6.

5 «Intimidades» (1929), o. c., II, 748.

6 Goethe desde dentro (1932), o. c., V, 134. 
qué la manera más adecuada de explicar la naturaleza de la misma ha sido a partir de su carácter instancial.

\section{LA Llamada A UN DETERMINADO TIPO DE VIDA}

Al hacer referencia a la vida humana, Ortega afirma que la misma consiste en un proyecto individual que cada hombre debe intentar conocer y cumplir si desea tener una existencia auténtica. En la búsqueda por cumplir con este proyecto vital, el individuo no sólo cuenta con su «yo» — esto es, con aquel personaje íntimo que busca realizarse-, sino también con la circunstancia que le es propia y que, como tal, por momentos facilitará y por momentos dificultará la realización de ese proyecto.

Esta circunstancia consiste en un repertorio de posibilidades que a cada instante se presentan ante el individuo y que le obligan a decidirse. Para poder elegir, el hombre se representa los diversos tipos de vida al que cada una de ellas lo conduciría. Esto significa, evidentemente, que las mismas no se presentarán como siendo indistintas sino siempre con algún tipo de jerarquía: habrá entre ellas algunas que llamarán más su atención, que lo atraerán más. Y, en efecto, habrá una de ellas que le representará al individuo aquello que efectivamente tiene que ser. «Esta llamada hacia un cierto tipo de vida o, lo que es igual, de un cierto tipo de vida hacia nosotros, esta voz o grito imperativo que asciende de nuestro más íntimo fondo es la vocación » ${ }^{7}$, afirma Ortega.

Así, la vocación es presentada por Ortega como una voz interna, como un «grito imperativo» que, frente a los distintos programas vitales posibles, llama a cada individuo a elegir uno de ellos y a excluir los demás. Se trata de una voz que proviene del fondo insobornable, de aquel «núcleo último e individualísimo de la personalidad» ${ }^{8}$, tal como explica Ortega, y que le exige su ejecución. Si el individuo escucha esta llamada, elegirá aquella posibilidad que su vocación le haya señalado como la más apropiada en su circunstancia y se aproximará, entonces, a la realización de su proyecto vital. Si la desoye, en cambio, falsificará su propia vida y aniquilará un instante de su existencia.

Ahora bien, Ortega presenta al individuo como un ser libre, y esto en dos sentidos distintos. Por un lado, cada individuo es libre de escuchar su propia vocación y de decidir ser en su vida efectiva aquel que es por íntima necesidad. En otras palabras, el individuo es libre de elegir un modo de vida auténtico o, por el contrario, de optar por la falsificación de la misma. Por otro, el hombre deberá decidir a cada instante entre las diversas posibilidades que la circunstancia pone frente a él con el fin de alcanzar aquel modo de vida que desee. De esta manera, resulta claro que la vocación no le impone al individuo un camino a seguir, sino que se lo propone. Sin embargo, no se trata de una propuesta

7 Sobre las carreras (1934), o. c., V, 298

8 «Ideas sobre Pío Baroja» (1916), o. c., II, 225. 
indiferente: Ortega insiste en la necesidad de que el hombre se mantenga fiel a su proyecto vital y, por lo tanto, en la necesidad de que escuche aquella llamada de la vocación. Se trata, en todo caso, de la propuesta a la realización de una necesidad. Y si bien estará en manos del individuo decidir actuar conforme a aquella llamada o no hacerlo, lo cierto es que si no lo hace quitará realidad a su vida y, por ello, sentirá su propia existencia como la estrangulación de sí mismo. Por el contrario, en la medida en que hombre busca ser fiel a su vocación, se aproxima a la verdad de su vida y, por lo tanto, a su propia autenticidad'.

Es frecuente suponer que la vocación de un individuo coincide con el esquema general de vida que está contenido en el nombre de un oficio o profesión. Sin embargo, Ortega buscará en más de una ocasión diferenciar estos dos términos. «La estricta vocación del hombre es vocación para una vida concretísima, individualísima, integral $»^{10}$, señala en 1934. Se trata, en todos los casos, de una llamada a una trayectoria individual que el hombre debe elegir para llegar a ser aquel que es por íntima necesidad. Esto es, una llamada a un modo de vida tan singular y concreto como lo es cada individuo. «Esta es la diferencia entre vocación y profesión. Las profesiones son realidades que pertenecen a la «vida colectiva». Y todo lo colectivo es, en efecto, genérico, típico, estereotipado» ${ }^{11}$, explica.

Sin embargo, se suele hacer referencia a las distintas vocaciones con términos genéricos referidos a profesiones u oficios de los individuos. Pareciera que uno tiene vocación de ser, por ejemplo, maestro, pintor o intelectual, mientras que estos no son más que esquemas sociales de vida en los que un individuo, por libre elección, podrá alojar la suya propia. Sin embargo, es evidente que los mismos hacen referencia a un único ámbito de la vida del individuo y excluyen los demás ${ }^{12}$. Por otra parte, si bien estas ocupaciones pueden permitir la

9 Esta noción de verdad en relación al hombre y su vida será central en Ortega. En ese sentido, en 1932 afirmará: «El problema sustancial, originario, y en este sentido único, es encajar yo en mí mismo, coincidir conmigo, encontrarme a mí mismo». [«Para el archivo de la palabra» (1932), o. c., V, 86].

10 «Sobre las carreras» (1934), o. c., V, 301.

11 «[Prólogo a Introducción a las ciencias del espíritu, de Wilhelm Dilthey]» (1946), IX, 726.

12 Con respecto a este punto, resulta interesante la lectura que realiza Javier SAN MARTíN [«Vocación y profesión. Bases orteguianas para una ética del futuro», en: CERezo GaLÁn, P. (ed.), Ortega en perspectiva, Instituto de España, Madrid, 2007, pp. 89-112]. Allí, el autor señala que, si bien vocación y profesión deben distinguirse dentro del planteamiento de Ortega, aún así la profesión es el ámbito en el cual se canaliza en mayor medida la vocación individual. En definitiva, aquello que cada individuo proyecta en el mundo se da inevitablemente en un contexto social, y lo que encuentra en éste son modelos de profesiones a los cuales adscribirse y bajo los cuales realizar la propia vida. Por esta razón, considera San Martín que desde 1934 en que publica «Sobre las carreras» (V, 297), Ortega estará cada vez más preocupado por el estudio de las profesiones, hasta abordar incluso en 1954, ya en sus últimos escritos, el tema de «Las profesiones liberales» $(\mathrm{X}, 426)$. 
realización de un aspecto de su vida — y, en esos casos, pueden ser fecundas ${ }^{13}$ siempre habrá innumerables modos de llevarlas adelante.

Por otra parte, debe señalarse que, si bien Ortega se refiera a la vocación como una "voz o grito imperativo que asciende de nuestro más íntimo fondo», esto no significa que la misma pueda conocerse por simple introspección. Por el contrario, afirma Ortega, la misma se vuelve inaccesible cuando nos volvemos de manera permanente hacia nuestra intimidad. «Buscar es una operación contemplativa, intelectual. Sólo se contemplan, se buscan cosas. Pero la norma surge en la acción. En el choque enérgico con el fuera brota clara la voz del dentro como un programa de conducta ${ }^{14}$, explica. Así, si bien es necesario escuchar aquella voz interna, la misma sólo resuena en el choque con la circunstancia donde intenta realizarse.

Ahora bien, hasta aquí se ha señalado en qué consiste la llamada de la vocación y se la ha diferenciado de otros conceptos que, en el uso cotidiano, suelen confundirse con la misma. Sin embargo, aunque parece resultar claro qué entiende Ortega por vocación cuando utiliza este término, lo cierto es que se echa de menos una mayor precisión por parte del filósofo cuando busca explicar qué es la misma. En otras palabras, si bien Ortega presenta diversas notas características de la vocación, en ningún momento explica de manera explícita cuál es su naturaleza. Por esta razón, y para una mejor comprensión de este concepto, resulta necesario detenerse en este interrogante.

\section{Distintas LEcturas SOBRE LA NATURALEZA DE LA VOCACiÓN}

A partir de lo explicado en el apartado anterior, queda claro que la utilización por parte de Ortega del concepto de vocación radica en la necesidad de hacer referencia a la llamada hacia un determinado tipo de vida que cada individuo debe escuchar a fin de poder llevar adelante una vida auténtica. En efecto, si se hace referencia a su etimología, puede verse que el término en sí mismo proviene de la voz latina vocare - llamada, acto de llamar- del cual se deriva vocatio — vocación-. Sin embargo, el interrogante que aún queda abierto consiste en saber en qué consiste aquella llamada. Es decir, cuál es, en efecto, su naturaleza.

Una de las interpretaciones que se ha hecho al respecto es aquella que presenta Beatriz Larrea Jaspe en su artículo «El sentido de la vocación en Ortega» ${ }^{15}$. Allí, la autora afirma que el concepto de vocación que Ortega utiliza hace referencia a algo similar a una «voz de la conciencia». Para poder afirmar esto, la

13 La razón histórica [curso de 1944], o. c., IX, 653

14 Goethe desde dentro (1932), o. c., V, 148.

15 Larrea Jaspe, B., «El sentido de la vocación en Ortega», en: Domínguez, A., Muñoz, J., De Salas, J. (coords.), El primado de la vida (cultura, estética y política en Ortega y Gasset), Ediciones de la Universidad de Castilla-La Mancha, Cuenca, 1997, pp. 53-68. 
autora se sirve de las palabras que Ortega pronuncia en 1940 frente al público de Buenos Aires. En aquella oportunidad, el filósofo explicaba que «el yo de cada uno de nosotros es ese ente extraño que, en nuestra íntima y secreta conciencia, sabe cada uno de nosotros que tiene que ser ${ }^{16}$. Y agregaba allí mismo que «esa íntima conciencia constantemente nos dice quién es ese que tenemos que ser, esa persona o personaje que tenemos que esforzarnos en realizar, y nos lo dice con una misteriosa voz interior que habla y no suena, una voz silente que no necesita palabras». Esa voz, agregaba Ortega un momento después, es, justamente, la voz de la vocación, aquella que nos susurra el imperativo de Píndaro: «Llega a ser el que eres». Esta explicación, entonces, conduce a Larrea a referirse a la vocación individual como «la voz de nuestra conciencia».

Sin embargo, debe decirse que esta expresión no se ajusta, en rigor, al concepto orteguiano de vocación. Si bien es cierto que Ortega utiliza efectivamente el término "conciencia» para referirse a aquel núcleo íntimo del individuo en el cual éste sabe cuál es aquel personaje que debe esforzarse por realizar, concebir la vocación como la voz de aquella conciencia implica poner en primer plano a esta última y sostener que es ella la que le exige al individuo aquella realización. Lo problemático de esta afirmación radica que en que la misma hace a un lado toda la crítica orteguiana al idealismo y parece olvidar el papel central que, para Ortega, tiene la circunstancia en el conocimiento de la vocación individual. Por esta razón, no puede considerarse a la vocación como la voz de la conciencia.

Otra explicación que se ha dado acerca de la naturaleza de la vocación consiste en asemejarla a una creencia, en el sentido orteguiano del término. Esta ha sido la interpretación presentada por Jaime de Salas ${ }^{17}$. Para poder comprender esta interpretación, se debe tener presente la distinción que realiza Ortega entre ideas y creencias. Las ideas, explica Ortega, no poseen un valor de realidad sino que actúan como pensamientos y sólo como tales. En ese sentido, en la medida en que son el resultado de la ocupación intelectual del individuo, las ideas «se tienen». Por su parte, en cambio, a las creencias no se llega tras un trabajo de entendimiento sino que operan desde el fondo del individuo cuando éste actúa o piensa en algo -y, en ese sentido, en las creencias «vivimos, nos movemos y somos ${ }^{18}$, explica Ortega. Al no ser el resultado de la actividad intelectual, no se suele tener conciencia expresa de ellas sino que las mismas actúan de forma latente en todo aquello que el individuo expresamente hace o piensa. En ese sentido, toda su conducta dependerá, finalmente, de cuál sea el sistema de sus creencias auténticas.

Una vez realizada esta distinción, De Salas explica que, tal como Ortega las presenta, las creencias no resultan todas iguales. Mientras que algunas de ellas son presupuestos cognoscitivos del comportamiento del individuo, existen

16 «Juan Luis Vives y su mundo» (1940), o. c., IX, 445.

17 De Salas, J., «Ortega y la ética de la perspectiva», en: Revista de Estudios Orteguianos, $\mathrm{N}^{\circ} 6,2003$, pp. 96-97.

18 Ideas y creencias (1940), o. c., V, 665. 
otras que, en cambio, conducen al sujeto a realizar determinados actos — siempre y cuando adscriba a ellas-. Estas creencias poseen, así, un alcance ético, en la medida en que guían al individuo a actuar de una determinada forma.

El motivo para realizar un paralelismo o asimilar la vocación a una creencia radica en que, tanto una como la otra, operan desde el fondo del individuo sin que éste sea realmente consciente de ellas. La vocación no consiste en un proyecto consciente que el individuo toma como modelo de acciones futuras, sino que en ella, al igual que en las creencias, el individuo está, vive, se mueve y es. En todo caso, por medio de la llamada que es la vocación, el individuo decidirá si desea llevar adelante aquel proyecto vital que le es propio y qué acciones realizará para cumplirlo, elección que lo conduciría a la autenticidad de su propia vida. En este sentido, De Salas explica que si bien el individuo puede reconocerse como llevando aquella vida que desea vivir, no logra en cambio una intuición propiamente dicha de la vocación, sino más bien un autorreconocimiento ante un proyecto que se encuentra llevando adelante.

Se debe recordar, una vez más, que De Salas asemeja la vocación a una creencia, esto es, establece un paralelismo en el modo en que las mismas intervienen en el accionar del individuo, pero no afirma en ningún momento que la vocación constituya efectivamente una creencia. Sin embargo, una lectura rápida podría llegar a confundir estos dos conceptos y, por lo mismo, conviene recordar que entre ellos radica una diferencia fundamental. Para poder explicar esta diferencia, podemos servirnos del mismo ejemplo que Ortega proporciona. El filósofo presenta el caso de un individuo que sale a la calle. Este individuo, por más consciente que pueda ser, en el mejor de los casos, de sus motivos para salir, de la resolución tomada y de la ejecución de cada uno de los movimientos con que camina, abre la puerta o baja la escalera, lo cierto es que seguramente en ningún momento se haga cuestión del hecho más importante de todos: si la calle estará allí fuera cuando salga. No piensa en ello, ni para afirmarlo, ni para negarlo ni para ponerlo en duda. Esto, evidentemente, no significa que la existencia de la misma no intervenga en su comportamiento. Por el contrario, el individuo cuenta con ella y por esto mismo no lo piensa. Se trata, explica Ortega, de una implicación latente del pensamiento que interviene en el accionar de la propia vida, sin que se traiga la misma a la conciencia ${ }^{19}$. En definitiva, que la calle estará allí afuera cuando salga se trata, sencillamente, de una creencia. Sin embargo, no se trata de una creencia individual. Es decir, cualquier otro individuo que, tal como él, decida salir, ordenará sus movimientos confiado en aquella creencia en común: que la calle estará allí afuera cuando salga. Con este ejemplo queda de manifiesto una de las notas características de las mismas: el hecho de ser, por lo general, compartidas con otros hombres. La vocación, en cambio, es siempre individual y, aunque ciertos elementos que la componen puedan ser compartidos, nunca habrá en efecto dos vocaciones idénticas.

\footnotetext{
$19 \quad$ Idem, 664
} 
La naturaleza de la vocación también se ha explicado a partir de la concepción orteguiana de la vida como aspiración. Este concepto es utilizado por Ortega en numerosas oportunidades haciendo referencia tanto a la vida humana como a la sociedad, y permite ver con claridad su concepción de la vida -individual y social - como futurición y permanente tarea. En ese sentido, y a modo de ejemplo, pueden encontrarse en su obra referencias a la aspiración de la vida humana en tanto proyecto, la aspiración de la democracia o de la vida política, la aspiración hacia un nuevo espíritu de época, la aspiración - propia del héroe - a innovar la vida, la aspiración de la filosofía, entre otros. Sin embargo, sucede una vez más que, si bien se trata de un término que puede ayudar a comprender el significado del concepto orteguiano de la vocación $-\mathrm{y}$ que permite poner especial énfasis en el anhelo y empeño que requiere una vida al servicio de la misma-, nuevamente deja de lado la explicación de su naturaleza metafísica.

De manera complementaria a este concepto, Cerezo explica la vocación como una inspiración originaria que aspira a su cumplimiento ${ }^{20}$. Este concepto, si bien no es utilizado por Ortega, permite mantener una analogía entre la vida personal y la creación artística que, de alguna manera, puede ser útil para comprender la naturaleza de la vocación. Así como sucede en la creación artística, explica Cerezo, también en la vida humana la inspiración viene precedida por ensayos o tanteos que poco a poco van delineando y dando forma a la vocación. Esta analogía permite, además, mostrar el papel central que cumplen las circunstancias a la hora de conocer y cumplir la vocación. Sin embargo, no deja de ser un término que hace referencia mucho más al funcionamiento de la misma que a su naturaleza.

En este sentido, resulta, además de interesante, muy apropiada la interpretación que realiza Gutiérrez Simón acerca de la vocación como instancia ${ }^{21}$. Para justificar esto, el autor se sirve de la explicación que presenta Rodríguez Huéscar. Este último, al hacer referencia al concepto de instancia, afirma que la misma «es previa al «ser» (y la que lo posibilita). La instancia no es -las «instancias» no son-ser, sino lo que nos hace «ser», y esto quiere decir, por lo pronto, lo que nos hace hacer, lo que hace que hagamos. [En otras palabras, es lo que nos hace que] hagamos nuestro ser (y, por supuesto, el de las cosas) al hacer [que] nos hagamos ${ }^{22}$. A esta explicación, que de por sí resulta ciertamente afín a la explicación orteguiana de la vocación, le agrega allí mismo: «La instancia nos insta, pues, a hacer — esto o aquello-para ser —esto o aquello-: lo que vamos a ser».

Luego de presentar esta caracterización general del término, Rodríguez Huéscar resume las cinco dimensiones esenciales de lo instante, entre las

20 Cerezo Galán, P., La voluntad de aventura, Ariel, Barcelona, 1984, pp. 356-364.

21 Gutiérrez Simón, R., «Sobre la interpretación del concepto orteguiano de "vocación" », en: Revista de Estudios Orteguianos, N ${ }^{\circ} 31$, 2015, pp. 125-126.

22 Rodríguez Huéscar, A., Éthos y logos, UNED, Madrid, 1996, pp. 38-39. Si no se indica otra cosa, se citará siempre respetando el énfasis original. 
cuales incluye la condición de aspirante del mismo. « «Instancia» es, en efecto, pretensión; las «cosas», los «algos», en su instar pretenden efectivamente algo, aspiran a algo, demandan algo» ${ }^{23}$. Lo instante es, también, aquello que «llama, voca, convoca o provoca ${ }^{24}$. Y, explicitando en mayor medida la afinidad de este término con el de vocación, Rodríguez Huéscar realiza una explicación del concepto de lo instante como aquello que implica proyecto y realización: "Yo me proyecto, pues, pero siempre en lo otro que yo o, si se quiere, en el mundo; (eso es lo que significa proyectar mi vida). La instancia, esa "última instancia» que, vista en otra perspectiva, sería la primera, me insta así a proyectarme y, consecuentemente, a realizarme "en vista de» ella» ${ }^{25}$.

Una vez realizada esta presentación del concepto de instancia, puede decirse que, así como ha señalado Gutiérrez Simón, el mismo es el que mejor explicaría la naturaleza metafísica del concepto orteguiano de vocación. Por otra parte, se trata de un concepto que reflejaría mucho más fielmente el modo en que la misma funciona en el contexto de la vida humana. En efecto, cuando Ortega hace referencia a la vocación, deja claro que se trata de una llamada que "convoca», que mueve a proyectarse, a hacer y a realizarse en el mundo, ya sea aceptándola o no. Ahora bien, debe tenerse presente que Rodríguez Huéscar no se refiere a la vocación cuando presenta su concepto de instancia, algo que deja de manifiesto que la misma - la vocación - no es el único elemento con carácter instancial que puede encontrarse. Sin embargo, se trata de un concepto que permite comprender mucho más fielmente la naturaleza metafísica de la vocación para poder, a partir de allí, proyectarla al ámbito de la ética.

\section{Algunas CONSIDERAciones finales SOBRE El CONCEPTO DE VOCACiÓn EN ORTEGA}

Estudiar el concepto orteguiano de vocación resulta fundamental por dos cuestiones. Por una lado, por la evidente centralidad de este concepto y por la importancia que adquiere a lo largo de sus obras. Por otro, por los numerosos interrogantes que ha dejado abiertos hasta el día de hoy. A lo largo de este trabajo, se ha intentado responder a uno de ellos, por considerar que se encuentra a la base de todos los demás. Este es, como se ha visto, el interrogante acerca de la naturaleza metafísica de la vocación.

Se ha sostenido aquí que la forma más apropiada en que se ha entendido la naturaleza de la vocación en la filosofía de Ortega es es aquella que la ha tomado como una «instancia» en los términos en que Rodríguez Huéscar utiliza esta palabra. Parafraseando a este último, la vocación convoca al hombre y lo conduce a hacer su propio ser. Sin embargo, a partir de la presentación realizada hasta aquí, uno puede inferir que para Ortega esto nunca es posible

$23 \quad$ Idem, p. 43.

24 Idem, p. 42.

25 Idem, p. 43. 
de modo absoluto. Es decir, si bien el concepto de vocación es central en su planteamiento, lo cierto es que el cumplimiento de la misma es presentado por él con carácter utópico.

Esto no constituye, sin embargo, un signo negativo de la misma sino que, en todo caso, deja de manifiesto que la vocación funciona como un resorte que lanza al individuo a buscar su realización aún teniendo conciencia del fracaso. La búsqueda permanente de conocer la individual vocación y de cumplirla conduce al hombre a ponerse en movimiento. Porque las cosas, sostiene Ortega, «no como poseídas u obtenidas contribuyen a hacernos felices, sino como motivos de nuestras actividad, como materia sobre la cual ésta se dispare y de mera potencia pase a ejercicio ${ }^{26}$. De esta manera, si bien, en palabras de Ortega, el hombre es «un personaje que no se realiza nunca del todo, una utopía incitante, una leyenda secreta que cada cual guarda en lo más hondo de su pecho ${ }^{27}$, el hecho de que exista permanentemente una distancia infranqueable entre el proyecto vital y el ser efectivo del hombre fomenta en él un esfuerzo sin límites que puede conducirlo constantemente hacia su propio perfeccionamiento.

$\mathrm{Al}$ inicio de este trabajo se recordaban las palabras que Ortega pronunciaba ante sus alumnos universitarios en el curso 1930-1931. Allí mismo, un momento después de explicar la vida como proyecto, el filósofo agregaba que aquello podía entenderse en tres sentidos distintos. En primer lugar, que yo soy el que aún no se ha realizado y, en ese sentido, soy mero proyecto. En segundo lugar, que yo soy el que aspira o pugna por ser realizado y, en ese sentido, soy proyección. Y, en tercer lugar, que yo soy el que inexorablemente exige ser realizado, aunque esta realización sea, en efecto, imposible. En este tercer sentido, agrega, soy vocación.

El hecho de valorar de esta manera el esfuerzo que conlleva vivir una vida al servicio de la vocación, aun teniendo permanente conciencia del fracaso, deja de manifiesto que en este curso de 1930 Ortega insistía una vez más en aquello que comprendió y que buscó transmitir en toda su filosofía: que únicamente entendiendo el cumplimiento de la vocación individual como aspiración y demanda permanente es que se pone en evidencia la exigencia que existe en todo individuo, sin ninguna distinción, de buscar a cada instante y libremente la propia superación como único modo de orientarse hacia su plenitud.

Pontificia Universidad Católica Argentina

Mora Perpere Viñuales moraperpere@uca.edu.ar

[Artículo aprobado para publicación en febrero de 2020]

26 «Ideas sobre Pío Baroja» (1916), o. c., II, 222.

27 Ensimismamiento y alteración (1939), o. c., V, 541. 